\title{
Mechanism of Self-protection in a Puromycin-producing Micro-organism
}

\author{
By MASANORI SUGIYAMA, * SOON-YOUNG PAIK $\dagger$ \\ AND RYOSAKU NOMI \\ Department of Fermentation Technology, Faculty of Engineering, Hiroshima University, \\ Saijo-cho, Higashi-Hiroshima 724, Japan
}

(Received 26 September 1984 ; revised 21 February 1985)

\begin{abstract}
Puromycin is a potent inhibitor of bacterial protein synthesis, but puromycin-producing Streptomyces alboniger KCC S- 0309 is tolerant to the antibiotic in vivo. Puromycin bound to both $30 \mathrm{~S}$ and $50 \mathrm{~S}$ ribosomal subunits from $S$. alboniger and inhibited polyuridylate-directed polyphenylalanine synthesis by the ribosomes. However, the organism possessed a novel puromycin-inactivating enzyme which acetylated the antibiotic at the 2"- $\mathrm{NH}_{2}$ group of the $O$-methyltyrosine moiety.
\end{abstract}

\section{INTRODUCTION}

The micro-organisms which produce antibiotic inhibitors of protein synthesis must be protected from the lethal effect of their own antibiotics. The producers of thiostrepton (Cundliffe, 1978; Cundliffe \& Thompson, 1979; Thompson \& Cundliffe, 1981), erythromycin (Teraoka \& Tanaka, 1974; Skinner \& Cundliffe, 1982), noshiheptide (Cundliffe \& Thompson, 1981), istamycin (Yamamoto et al., 1981) and berninamycin (Thompson et al., 1982) all possess drug-resistant ribosomes. Enzymic inactivation of streptomycin (Sugiyama et al., 1980, 1981 a,b, 1982, 1983), neomycin (Thompson et al., 1980; Hotta et al., 1981), kanamycin (Satoh et al., 1975; Hotta et al., 1981), streptothricin (Keeratipibul et al., 1983), viomycin and capreomycin (Skinner \& Cundliffe, 1980) by their producers has also been demonstrated. Furthermore, in the production of streptomycin (Sugiyama et al., 1981b; Nimi et al., 1981) and chloramphenicol (Malik \& Vining, 1972), it has been suggested that a decrease in cell permeability to the antibiotic at the idiophase of culture plays an important role in self-protection of the producer.

Puromycin, a functional analogue of aminoacyl tRNA, inhibits protein synthesis by substituting for the incoming coded aminoacyl tRNA, and serving as an acceptor for the nascent peptide chain of ribosome-bound peptidyl tRNA (Nathans \& Lipman, 1961). Streptomyces alboniger, a puromycin producer, is tolerant to its own antibiotic product. The organism has been reported to express an enzyme activity which acetylates puromycin by using acetyl coenzyme A (Pérez-González et al., 1983). The acetylated puromycin showed no antibiotic activity against Bacillus subtilis. It was suggested that puromycin was converted into $N$-acetyl-puromycin. The acetylation of puromycin and the self-protection of the producer were proposed by rather indirect procedures.

We also showed acetylation of puromycin by the producer, and have purified the acetyltransferase. In the present paper, we show that puromycin inhibits protein synthesis of the producer by binding to both $30 \mathrm{~S}$ and $50 \mathrm{~S}$ subunits of ribosomes. Protection of protein synthesis by puromycin-acetyltransferase was ascertained by using an in vitro protein-synthesizing system. The site of acetylation of puromycin was determined physico-chemically. The substrate specificity of the puromycin acetyltransferase was also defined.

† Present address: Department of Food Technology, College of Agriculture, Korea University, Seoul 132, Republic of Korea. 


\section{METHODS}

Organism. Puromycin-producing Streptomyces alboniger KCC S-0309 was used.

Chemicals. Puromycin dihydrochloride was purchased from Sigma, and $\left[8(\mathrm{n})-{ }^{3} \mathrm{H}\right]$ puromycin dihydrochloride from Amersham. Neomycin sulphate, kanamycin sulphate and chloramphenicol were purchased from Nippon Kayaku, Meiji Seika Kaisha and Boehringer, respectively.

Preparation of ribosomes and S-150 fraction. This was done according to the methods of Sugiyama et al. (1983), using mycelia grown in GMP medium $[1 \%(\mathrm{w} / \mathrm{v})$ glucose, $0.5 \%(\mathrm{w} / \mathrm{v}) \mathrm{NaCl}, 0.4 \%(\mathrm{w} / \mathrm{v})$ peptone, $0.2 \%(\mathrm{w} / \mathrm{v})$ yeast extract, $0.2 \%(\mathrm{w} / \mathrm{v})$ meat extract, $\left.0.025 \%(\mathrm{w} / \mathrm{v}) \mathrm{MgSO}_{4} .7 \mathrm{H}_{2} \mathrm{O}, \mathrm{pH} 7.0\right]$ to an OD of approximately $250 \mathrm{Klett}$ units.

Assay of protein synthesis in vitro. Polyuridylate-directed polyphenylalanine synthesis was assayed as described previously (Sugiyama et al., 1983).

Puromycin tolerance of the producer in vivo. One loopful of spore mass was inoculated into $10 \mathrm{ml}$ GMP medium and cultivated at $28^{\circ} \mathrm{C}$ for $48 \mathrm{~h}$ under shaking. A sample $(0 \cdot 1 \mathrm{ml})$ of this culture broth was transferred to $10 \mathrm{ml}$ of the same medium containing a given concentration of puromycin. Growth was measured after incubation at $28^{\circ} \mathrm{C}$ for $48 \mathrm{~h}$ under shaking.

Purification of acetylated puromycin. A solution (approximately $5 \mathrm{ml}$ ) containing $20 \mathrm{mg}(37 \mu \mathrm{mol})$ puromycin dihydrochloride, $30.6 \mathrm{mg}$ ( $38 \mu \mathrm{mol})$ acetyl coenzyme $\mathrm{A}$ and $\mathrm{S}-150$ fraction (16 mg protein) from $S$. alboniger was incubated for $1 \mathrm{~h}$ at $28^{\circ} \mathrm{C}$, and was extracted with $10 \mathrm{ml}$ ethyl acetate. The organic phase was washed twice with water by mixing vigorously and adjusting the $\mathrm{pH}$ value to 4 , so that any trace of puromycin dissolved in the ethyl acetate would be extracted into the water phase. The organic phase was dehydrated with anhydrous sodium sulphate and was evaporated to obtain acetylpuromycin. The purity of acetylpuromycin was confirmed by TLC on a silica gel sheet (Merck Art. 5553) using a solvent system of $n$-butanol/acetic acid/water (4:1:2, by vol.). Since acetylpuromycin gave a negative ninhydrin reaction, it was detected by spraying with $10 \%(\mathrm{v} / \mathrm{v})$ sulphuric acid.

\section{RESULTS}

\section{Susceptibility of the ribosomes of $S$. alboniger to puromycin}

When S. alboniger KCC S-0309 was cultivated in GMP medium with and without puromycin, as described in Methods, it was tolerant of puromycin up to $100 \mu \mathrm{g} \mathrm{ml}^{-1}$ with no change in the extent of growth. However, protein synthesis in this strain was strongly inhibited by puromycin when it was examined in an in vitro system constructed with the ribosomes and S-150 fraction (data not shown).

Binding of puromycin to the ribosomes was examined using dissociated ribosomes which were incubated with $\left[{ }^{3} \mathrm{H}\right]$ puromycin and fractionated by sucrose density gradient centrifugation. The peaks of $\left[{ }^{3} \mathrm{H}\right]$ puromycin radioactivity appeared in the same fractions as the ribosomal $30 \mathrm{~S}$ and $50 \mathrm{~S}$ subunits (Fig. 1). From these results, it can be concluded that the ribosomes of strain KCC S-0309 are susceptible to puromycin, suggesting that the organism must have a puromycin resistance mechanism other than ribosomal resistance.

\section{Inactivation of puromycin by the $S-150$ fraction from $S$. alboniger}

The antibiotic activity of puromycin disappeared during inactivation with acetyl coenzyme A and the S-150 fraction from strain KCC S-0309 (Fig. 2). Substitution of ATP for acetyl coenzyme $\mathrm{A}$ was ineffective. When a polyphenylalanine-synthesizing reaction mixture to which puromycin had been added was also supplemented with acetyl coenzyme $A$, the inhibitory effect of puromycin was completely suppressed. These results indicate that the puromycin-acetylating enzyme can protect protein synthesis in extracts of KCC S-0309 against the endogenous antibiotic product.

\section{Substrate specificity of the puromycin-acetylating enzyme}

Kanamycin, neomycin, streptothricin and chloramphenicol are known to be inactivated by acetylation (Benveniste \& Davies, 1973; Satoh et al., 1975; Shaw \& Hopwood, 1976; Thompson et al., 1980; Keeratipibul et al., 1983). We tested the puromycin acetyltransferase from strain KCC S-0309 to see whether it could acetylate these antibiotics. The S-150 fraction from our strain inactivated streptothricin as well as puromycin (Fig. 2). However, it should be pointed out that streptothricin was also inactivated by the S-150 fraction in the absence of added acetyl coenzyme A. The S-150 fraction appears to have some streptothricin-inactivating activity other than acetylation. 


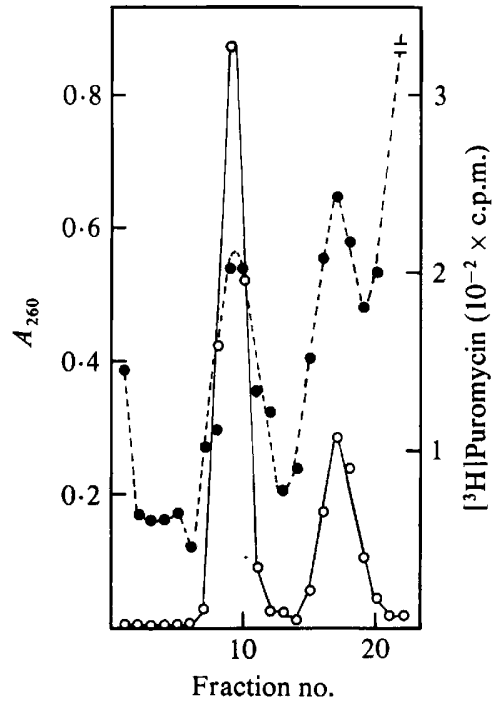

Fig. 1. Binding of $\left[{ }^{3} \mathrm{H}\right]$ puromycin to ribosomal subunits from $S$. alboniger. Ribosomes were dissociated by dialysis against buffer consisting of $10 \mathrm{~mm}-\mathrm{Tris} / \mathrm{HCl}(\mathrm{pH} 7.65), 30 \mathrm{mM}-\mathrm{NH}_{4} \mathrm{Cl}, 0.3 \mathrm{~mm}$-magnesium acetate and $6 \mathrm{~mm}-2$-mercaptoethanol. The dissociated preparation ( $355 \mathrm{pmol}$ ribosomes) was incubated with $625 \mathrm{pmol}\left[{ }^{3} \mathrm{H}\right]$ puromycin at $28^{\circ} \mathrm{C}$ for $1 \mathrm{~h}$ and then layered onto density gradients of 10 to $30 \%$ $(\mathrm{w} / \mathrm{v})$ sucrose in the same buffer. The samples were then centrifuged at $70000 \mathrm{~g}$ for $17 \mathrm{~h} . \mathrm{O}, A_{260} ; \mathrm{O}$, radioactivity of $\left[{ }^{3} \mathrm{H}\right]$ puromycin.

(a)

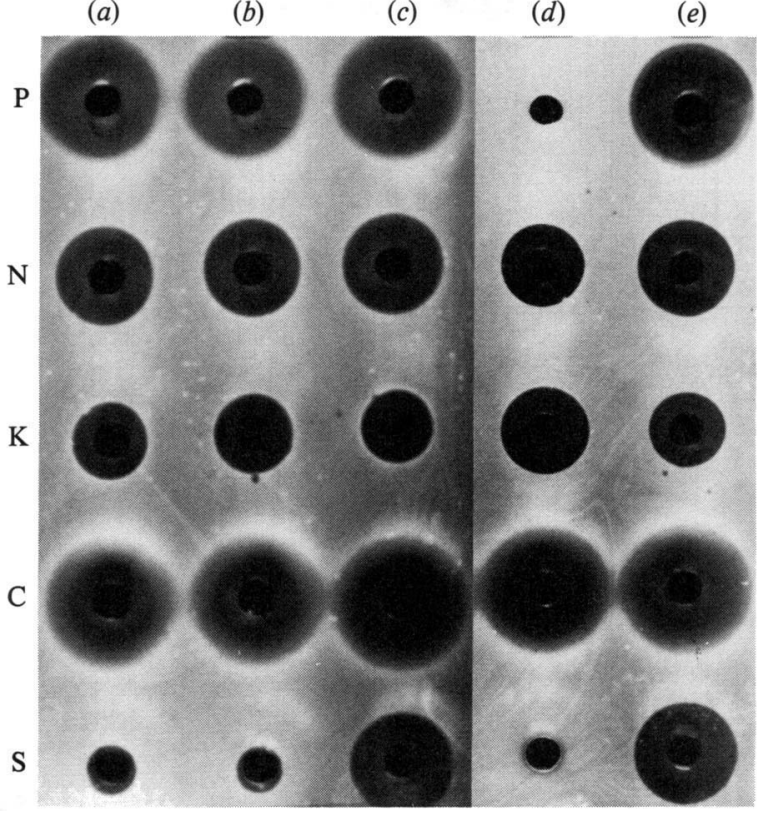

Fig. 2. Substrate specificity of the puromycin-acetylating enzyme. Reaction mixtures $(100 \mu \mathrm{l}$ in total) contained $80 \mathrm{~mm}$-Tris/ $\mathrm{HCl}(\mathrm{pH} \mathrm{7.65),} 10 \mathrm{~mm}$-magnesium acetate, $6 \mathrm{~mm}-2$-mercaptoethanol and antibiotic substrate $\left(100 \mu \mathrm{g} \mathrm{ml}^{-1}\right)$ together with the following: $(a) \mathrm{S}-150$ fraction $(216 \mu \mathrm{g}$ protein), (b) S150 fraction and ATP ( $2 \mathrm{mM}),(c)$ ATP, (d) S-1 50 fraction and acetyl coenzyme A ( $2 \mathrm{mM})$, or (e) acetyl coenzyme A. Substrate antibiotics used were puromycin dihydrochloride $(\mathrm{P})$, neomycin sulphate $(\mathrm{N})$, kanamycin sulphate $(\mathrm{K})$, chloramphenicol $(\mathrm{C})$ and streptothricin $(\mathrm{S})$. The reaction mixtures were incubated at $28^{\circ} \mathrm{C}$ for $30 \mathrm{~min}$ and then subjected to antibiotic assay by an agar diffusion method using Bacillus subtilis IFO 3134 as a test organism. 

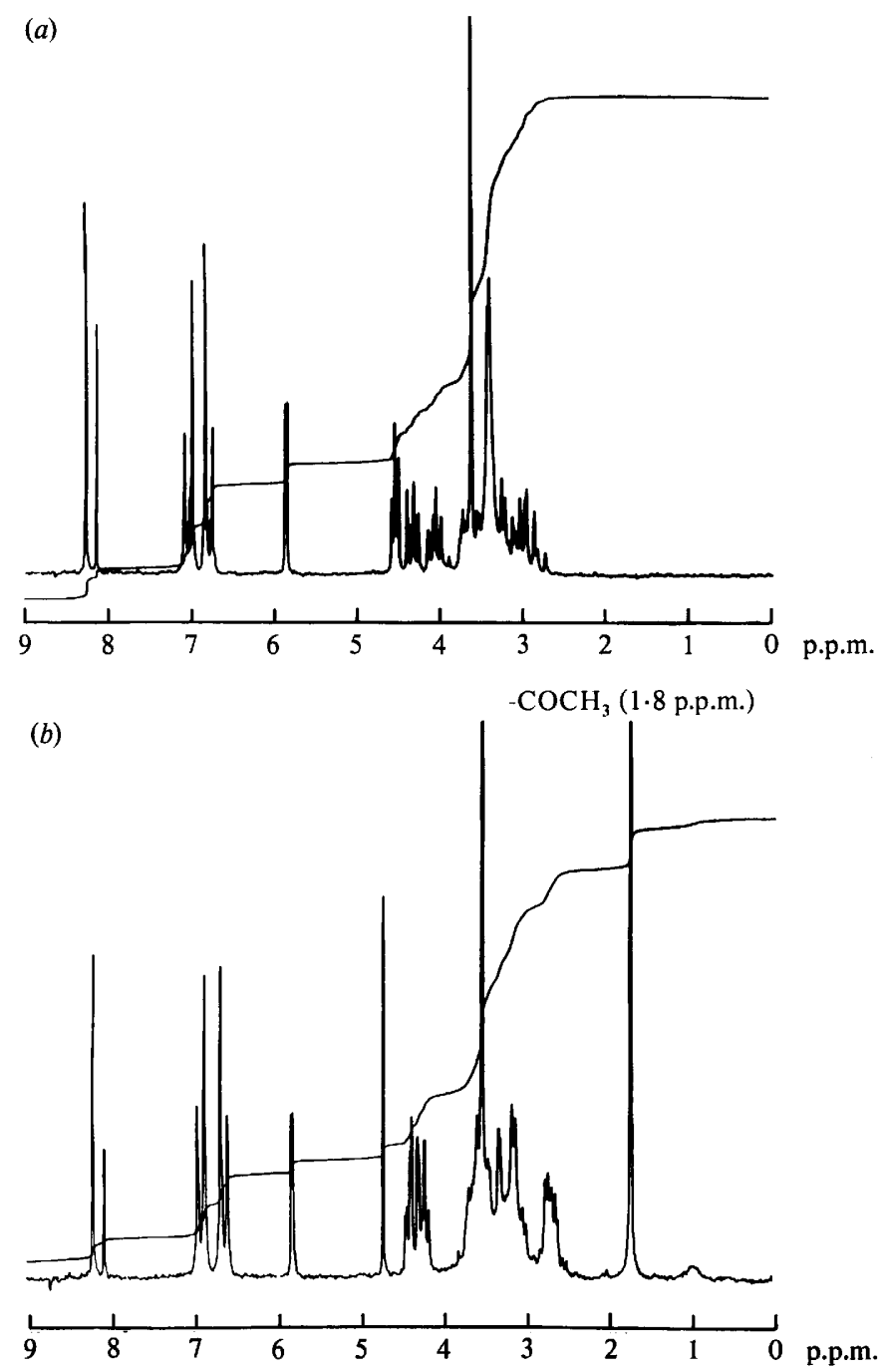

Fig 3. ${ }^{1} \mathrm{H}$ NMR spectra of puromycin and the acetylated product. The solvent systems of $\mathrm{D}_{2} \mathrm{O}$ and $\mathrm{D}_{2} \mathrm{O}+\mathrm{DCl}$ were used for $(a)$ puromycin and $(b)$ the acetylated product, respectively.

Table 1. Chemical shift of ${ }^{13}$ C NMR

\begin{tabular}{|c|c|c|c|c|c|}
\hline \multirow[b]{2}{*}{ Atom* } & \multicolumn{2}{|c|}{$\delta$ (p.p.m.) } & \multirow[b]{2}{*}{ Atom* } & \multicolumn{2}{|c|}{$\delta$ (p.p.m.) } \\
\hline & Puromycin & Acetylpuromycin & & Puromycin & Acetylpuromycin \\
\hline 2 & $146 \cdot 0$ & $146 \cdot 5$ & $2^{\prime \prime}$ & $55 \cdot 4$ & $56 \cdot 3$ \\
\hline 4 & 148.4 & 148.9 & $3^{\prime \prime}$ & $36 \cdot 9$ & $37 \cdot 4$ \\
\hline 5 & $120 \cdot 3$ & $120 \cdot 3$ & $4^{\prime \prime}$ & $127 \cdot 2$ & $129 \cdot 4$ \\
\hline 6 & $149 \cdot 5$ & $148 \cdot 5$ & $5^{\prime \prime}$ & $115 \cdot 3$ & $115 \cdot 0$ \\
\hline 8 & $141 \cdot 3$ & $141 \cdot 5$ & $6^{\prime \prime}$ & $131 \cdot 5$ & $131 \cdot 2$ \\
\hline $6-\mathrm{N}-\mathrm{CH}_{3}$ & $41 \cdot 3$ & $41 \cdot 8$ & $7^{\prime \prime}$ & $159 \cdot 3$ & $158 \cdot 7$ \\
\hline $1^{\prime}$ & $90 \cdot 8$ & $91 \cdot 0$ & $8^{\prime \prime}$ & $131 \cdot 5$ & $131 \cdot 2$ \\
\hline $2^{\prime}$ & $74 \cdot 1$ & $74 \cdot 5$ & $9^{\prime \prime}$ & $115 \cdot 3$ & $115 \cdot 0$ \\
\hline $3^{\prime}$ & $56 \cdot 3$ & $56 \cdot 3$ & $7^{\prime \prime}-\mathrm{O}-\mathrm{CH}_{3}$ & $51 \cdot 4$ & $51 \cdot 1$ \\
\hline $4^{\prime}$ & $83 \cdot 2$ & $83 \cdot 3$ & $\mathrm{O}$ & & \\
\hline $5^{\prime}$ & $61 \cdot 0$ & $61 \cdot 0$ & $\begin{array}{l}\mathrm{C}-\mathrm{CH}_{3} \\
\mathrm{O}\end{array}$ & - & $174 \cdot 8$ \\
\hline $1^{\prime \prime}$ & $170 \cdot 1$ & $174 \cdot 2$ & $\stackrel{\mathrm{C}}{\mathrm{C}}-\mathrm{CH}_{3}$ & - & $22 \cdot 5$ \\
\hline
\end{tabular}

* The numbering system identifying the carbon atoms is shown in Fig. 5. The relevant carbon atom in the acetyl group is shown in bold type. 


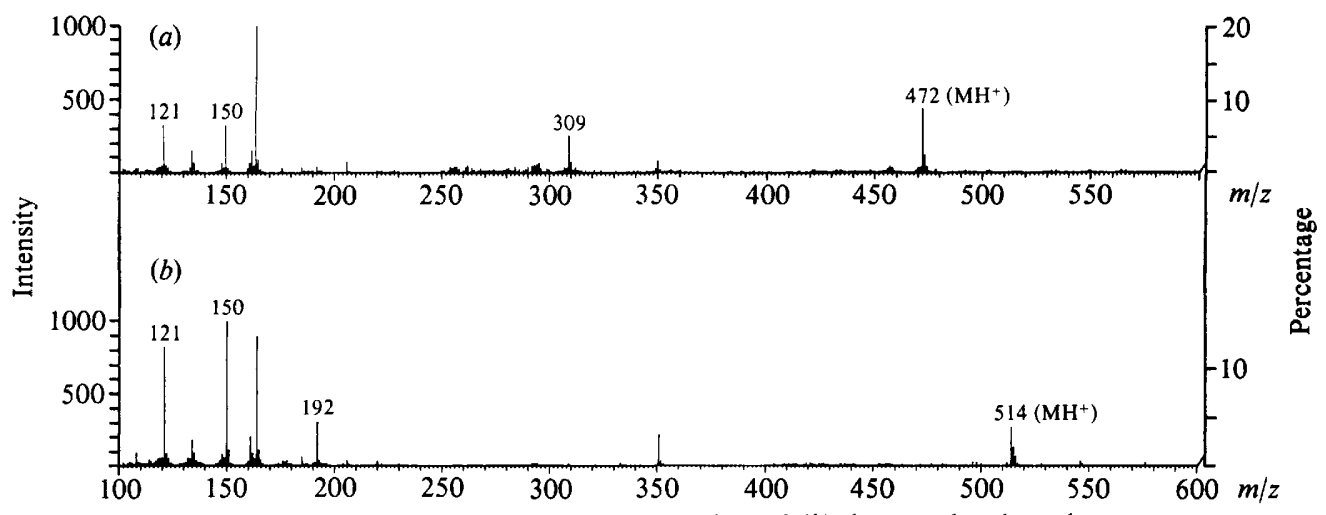

Fig. 4. FAB mass spectra of $(a)$ puromycin and $(b)$ the acetylated product.

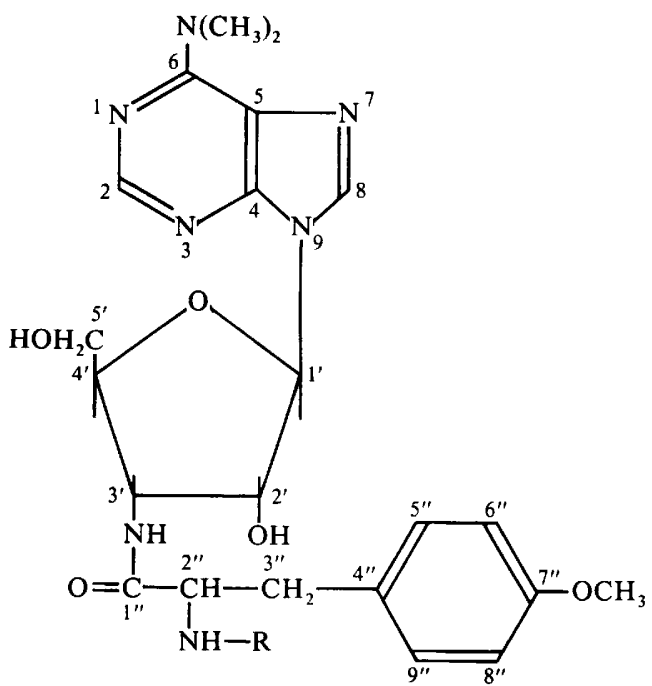

Fig. 5. The chemical structure of puromycin $(\mathrm{R}=\mathrm{H})$ and the acetylated product $\left(\mathrm{R}=\mathrm{COCH}_{3}\right)$.

\section{Site of acetylation of puromycin}

Acetylated puromycin, prepared enzymically, was purified and compared with authentic puromycin by TLC as described in Methods. The acetylated puromycin gave a single spot and was less polar than puromycin (data not shown). The acetylated product was analysed by ${ }^{1} \mathrm{H}$ NMR. The spectrum was similar to that of puromycin except that the acetylated puromycin gave a distinctive singlet at 1.8 p.p.m. representing a $\mathrm{CH}_{3} \mathrm{CO}$-residue (Fig. 3). This residue was confirmed by analysis by ${ }^{13} \mathrm{C}$ NMR. The acetylated puromycin had two specific signals at 22.5 and 174.8 p.p.m., which were assigned to a primary and a quaternary carbon respectively, in addition to the same signals as puromycin (Table 1). In order to estimate the number of acetyl residues, the molecular weight of the modified drug was determined from the FAB mass spectrum. The protonated molecular ions $\left(\mathrm{MH}^{+}\right)$of puromycin and the acetylated product gave $m / z$ of 472 and 514 , respectively (Fig. 4). The latter value is consistent with monoacetyl puromycin. A fragment ion at $m / z 192$ corresponding to an $N$-acetyl- $O$-methyltyrosine residue appeared in the mass spectrum of acetylated puromycin, showing that the acetyl group was introduced into the amino group of the $O$-methyltyrosine moiety in puromycin. In the infra red spectrum, no absorbance assignable to the ester of a carboxyl group was observed in acetylated puromycin (data not shown). These results indicated that puromycin was inactivated by $\mathrm{N}$ acetylation and not by $O$-acetylation. Thus the chemical structure of the acetylated puromycin was determined to be that shown in Fig. 5. 


\section{DISCUSSION}

Acetylpuromycin was produced from puromycin using the S-150 fraction of $S$. alboniger plus acetyl coenzyme A, and was then purified. The acetylated site was physico-chemically identified as the $2^{\prime \prime}-\mathrm{NH}_{2}$ group of the $O$-methyltyrosine moiety. Puromycin $2^{\prime \prime}-\mathrm{N}$-acetyltransferase was able to protect the protein synthetic apparatus in extracts of the puromycin producer.

It was also shown in the present study that the ribosomes of the puromycin producer were sensitive to the endogenous antibiotic. Puromycin bound to both the $30 \mathrm{~S}$ and $50 \mathrm{~S}$ subunits. According to Olson et al. (1982) and Grant et al. (1983), binding of puromycin to ribosomes of Escherichia coli also took place on both the $30 \mathrm{~S}$ and 50S subunits, and each subunit had two binding regions. Many antibiotics which inhibit bacterial protein synthesis have been reported to bind to either one of the two ribosomal subunits. Puromycin is unusual in binding to both of the subunits; the functional differences arising from this remain to be determined.

Several antibiotic-producing micro-organisms have been reported to produce enzymes that inactivate their own products. But there is no definitive evidence that any producer is protected by its inactivating enzyme alone. We have already reported that the ribosomes of streptomycinproducing Streptomyces griseus were sensitive to streptomycin, but that they were protected by streptomycin 6-phosphotransferase produced by the organism (Sugiyama et al., 1980, 1981 a, b, $1982,1983)$. While the production of this inactivating enzyme increased with the age of mycelium, sensitivity of ribosomes and also the ability of mycelium to take up extracellular streptomycin decreased at the idiophase of culture (Sugiyama et al., 1981 b). Owing to these three protecting measures $S$. griseus appeared to be able to produce a large amount of streptomycin. We are now studying the puromycin producer to see whether it shows a similar change in ribosomal sensitivity and uptake of puromycin during cultivation.

We are grateful to Dr A. Seino, the Institute of Physical and Chemical Research, for the supply of Streptomyces alboniger KCC S-0309 and to Dr M. Hayashi, the Research Centre, Toyo Jozo Co. Ltd, for measurement of ${ }^{1} \mathrm{H}$ and ${ }^{13} \mathrm{C}$ NMR mass spectra and infra red spectra. We thank Professor S. Nakamura, School of Medicine, Hiroshima University, for his valuable discussions. We are also grateful to Drs Y. Murooka and O. Nimi, Faculty of Engineering, Hiroshima University, for their useful advice.

\section{REFERENCES}

Benveniste, R. \& Davies, J. (1973). Aminoglycoside antibiotic-inactivating enzymes in actinomycetes similar to those present in clinical isolates of antibiotic-resistant bacteria. Proceedings of the National Academy of Sciences of the United States of America 70, 2276-2280.

Cundliffe, E. (1978). Mechanism of resistance to thiostrepton in the producing-organism Streptomyces azureus. Nature, London 272, 792-795.

Cundliffe, E. \& Thompson, J. (1979). Ribose methylation and resistance to thiostrepton. Nature, London 278, 859-861.

Cundliffe, E. \& Thompson, J. (1981). The mode of action of noshiheptide (multiomycin) and the mechanism of resistance in the producing organism. Journal of General Microbiology 126, 185-192.

Grant, P. G., Olson, H. M., Gliz, D. G. \& Cooperman, B. S. (1983). Puromycin binding to the small subunits of Escherichia coli ribosomes. Journal of Biological Chemistry 258, 11305-11312.

Hotta, K., Yamamoto, H., Okami, Y. \& Umezawas, H. (1981). Resistance mechanisms of kanamycin-, neomycin-, and streptomycin-producing streptomycetes to aminoglycoside antibiotics. Journal of Antibiotics 34, 1175-1182.

Keeratipibul, S., Sugiyama, M. \& Nomi, R. (1983). Mechanism of resistance to streptothricin of a producing microorganism. Biotechnology Letters $\mathbf{5}$, 441-446.

MaLIK, V. S. \& VINING, L. C. (1972). Chloramphenicol resistance in a chloramphenicol-producing Streptomyces. Canadian Journal of Microbiology 18, 583-590.

Nathans, D. \& Lipmann, F. (1961). Amino acid transfer from aminoacyl-ribonucleic acids to protein on ribosomes of Escherichia coli. Proceedings of the National Academy of Sciences of the United States of America 47, 496-504.

Nimi, O., Sugiyama, M., Kameoka, H., Tomoeda, H., ONO, K. \& NomI, R. (1981). Fate of streptomycin in mycelium of producer organism. Biotechnology Letters 3, 239-244.

Olson, H. M., Grant, P. G., Cooperman, B. S. \& GLITZ, D. G. (1982). Immunoelectron microscopic localization of puromycin binding on the large subunit of the Escherichia coli ribosome. Journal of Biological Chemistry 257, 2649-2656.

Pérez-González, J. A., Vara, J. \& Jiménez, A. (1983). Acetylation of puromycin by Streptomyces alboniger, the producing organism. Biochemical and Biophysical Research Communications 113, 772777.

Satoh, A., OGawa, H. \& Satomura, Y. (1975). Effect of sclerin on production of the aminoglycoside antibiotics accompanied by salvage function in 
Streptomyces. Agricultural and Biological Chemistry 39, 1593-1598.

SHAW, W. V. \& HoPwOOD, D. A. (1976). Chloramphenicol acetylation in Streptomyces. Journal of General Microbiology 94, 159-166.

SkinNer, R. H. \& Cundliffe, E. (1980). Resistance to the antibiotics viomycin and capreomycin in the Streptomyces species which produce them. Journal of General Microbiology 120, 95-104.

Skinner, R. H. \& Cundliffe, E. (1982). Dimethylation of adenine and the resistance of Streptomyces erythreus to erythromycin. Journal of General Microbiology 128, 2411-2416.

Sugiyama, M., KobaYashi, H., Nimi, O. \& Nomi, R. (1980). Susceptibility of protein synthesis to streptomycin in streptomycin-producing Streptomyces griseus. FEBS Letters 110, 250-252.

Sugryama, M., Mochizuki, H., Nimi, O. \& Nomi, R. $(1981 a)$. Roles of streptomycin 6-kinase and ribosomal affinity to streptomycin in self-protection of streptomycin producer. Biotechnology Letters 3, 357362.

Sugiyama, M., Mochizuki, H., Nimi, O. \& Nomi, R. $(1981 b)$. Mechanism of protection of protein synthesis against streptomycin inhibition in a producing strain. Journal of Antibiotics 34, 1183-1188.

Sugiyama, M., Mochizuki, H., Nimi, O. \& Nomi, R. (1982). Assessment of competitive action of streptomycin 6-kinase and streptomycin 6-phosphatase in the in vitro protein synthesis of a streptomycin- producing microorganism. FEBS Letters 139, 331333.

Sugiyama, M., Sakamoto, M., Mochizuki, H., Nimi, O. \& NOMI, R. (1983). Purification and characterization of streptomycin 6-kinase, an enzyme implicated in self-protection of a streptomycin-producing micro-organism. Journal of General Microbiology 129, 1683-1687.

TeraokA, H. \& TANaKa, K. (1974). Properties of ribosomes from Streptomyces erythreus and Streptomyces griseus. Journal of Bacteriology 120, 316321.

Thompson, C. J., Ward, J. M. \& Hopwood, D. A. (1980). DNA cloning in Streptomyces: resistance genes from antibiotic-producing species. Nature, London 286, 525-527.

Thompson, J. \& Cundliffe, E. (1981). Purification and properties of an RNA methylase produced by Streptomyces azureus and involved in resistance to thiostrepton. Journal of General Microbiology 124, 291-297.

Thompson, J., Cundliffe, E. \& Stark, M. J. R. (1982). The mode of action of berninamycin and the mechanism of resistance in the producing organism, Streptomyces bernensis. Journal of General Microbiology 128, 875-884.

Yamamoto, H., HotTa, K., OKami, Y. \& Umezawa, H. (1981). Self-resistance of a Streptomyces which produces istamycin. Journal of Antibiotics 34, 824829. 